\title{
Comment on: Loureiro \& Rozenfeld "Epidemiology of sickle cell disease hospital admissions in Brazil"
}

\section{Comentário sobre: "Epidemiologia das internações por doença falciforme no Brasil", de Loureiro \& Rozenfeld}

Miami, May 8, 2006

Dear Editor,

We read with interest the report by Loureiro \& Rozenfeld on the epidemiology of sickle cell disease hospital admissions in Brazil. ${ }^{2}$ In this article, the authors reported median age at death in three Brazilian regions of 26.5 years, 30 years, and 31.5 years. They then compared these summaries with Jamaican median survival rates of 53 years for men and 58.5 years for women, ${ }^{4}$ and reported "an early lethality" reflecting "social inequalities that exist between Brazil and other countries".

In assuming the equivalence of median survival and median age at death, -the authors have made a simple error that is common in the epidemiological literature. Median survival is defined as the age at which $50 \%$ of the study population has died, and must additionally include participants that do not die. These living participants are accounted for using statistical techniques that remove or "censor" the live participant at their last known contact date within a study window.

In the Jamaican report, homozygous sickle cell (SS) disease was studied over a 10-year period, during which 290 out of 3,301 (8.8\%) patients died. In the same paper, median age at death was reported as 24.9 years for men, and 25.7 years for women. These fig- ures for Jamaicans with SS disease are directly comparable with, and broadly similar to the reported median ages at death in Bahia, Rio de Janeiro, and São Paulo. The dataset reported by Loureiro and Rozenfeld does not allow the calculation of median survival. It remains possible that median survival is similar to those identified in Jamaica and the USA. ${ }^{3}$

In a later paper from the Jamaican group it is shown that, in the absence of newborn screening for sickle cell disease, almost $65 \%$ of children affected by SS disease and not identified at birth will not benefit from important early-life clinical intervention. ${ }^{1}$ It is therefore likely that early deaths, even if they occurred in hospital, are not ascribed to SS disease, and this possibly leads to an optimistic median age at death when relying on hospital-based data.

In the coming decades more accurate information on median survival in homozygous sickle-cell disease will become available from patient groups such as the Jamaican Cohort Study, in which patients are identified at birth and prospectively followed. Until then, survival estimates will depend on the appropriateness of techniques used and assumptions made.

Klaas J. J. Wierenga

Dr. John T. Macdonald Foundation Center for Medical Genetics University of Miami, Miami, USA 


\section{REFEREN CES}

1. Hambleton IR, Wierenga KJ. Identifying homozygous sickle cell disease when neonatal screening is not available: a clinic-based observational study. J Med Screen. 2004;11:175-9.

2. Loureiro MM, Rozenfeld S. Epidemiology of sickle cell disease hospital admissions in Brazil. Rev Saúde Pública. 2005:39:943-9.

Rio de Janeiro, June 17, 2006

\section{Dear Editor,}

In reference to the letter from Dr Wierenga and Dr Hambleton, we agree with them in respect to their statement that median survival cannot be straightly compared to median age at death, as we have written in our article. However, as we estimated a very low age at death in these patients, we improperly concluded that there were differences in survival between countries, explaining the differences by social inequalities. Our data did not allow this comparison. The median survival in Brazilian sickle disease may
3. Platt OS, Brambilla DJ, Rosse WF, Milner PF, Castro $O$, Steinberg $M H$, et al. Mortality in sickle cell disease. Life expectancy and risk factors for early death. N Engl J Med. 1994;330:1639-44.

4. Wierenga KJ, Hambleton IR, Lewis NA. Survival estimates for patients with homozygous sickle-cell disease in Jamaica: a clinic-based population study. Lancet. 2001;357:680-3.

be similar to other countries estimates but unfortunately we have no awareness of any cohort study in Brazil on this subject. In fact, the age at death between Jamaica and Brazil can be comparable.

We thank the authors for their remarks and we expect to give notice on Brazilian sickle disease epidemiology soon.
Monique M. Loureiro Suely Rozenfeld Escola Nacional de Saúde Pública, Fundação Oswaldo Cruz 
This article has received corrections in agreement with the ERRATUM published in Volume 40 Number 5. 